\title{
Advanced Cathode Materials for Polymer Electrolyte Fuel Cells Based on Pt/ Metal Oxides: From Model Electrodes to Catalyst Systems
}

\author{
Emiliana Fabbris゙, Alexandra Pătru, Annett Rabis, Rüdiger Kötz, and Thomas J. Schmidt \\ §SCS-Metrohm Foundation Award for best oral presentation
}

\begin{abstract}
The development of stable catalyst systems for application at the cathode side of polymer electrolyte fuel cells (PEFCs) requires the substitution of the state-of-the-art carbon supports with materials showing high corrosion resistance in a strongly oxidizing environment. Metal oxides in their highest oxidation state can represent viable support materials for the next generation PEFC cathodes. In the present work a multilevel approach has been adopted to investigate the kinetics and the activity of Pt nanoparticles supported on $\mathrm{SnO}_{2}$ based metal oxides. Particularly, model electrodes made of $\mathrm{SnO}_{2}$ thin films supporting Pt nanoparticles, and porous catalyst systems made of $\mathrm{Pt}$ nanoparticles supported on $\mathrm{Sb}$-doped $\mathrm{SnO}_{2}$ high surface area powders have been investigated. The present results indicate that $\mathrm{SnO}_{2}$-based supports do not modify the oxygen reduction reaction mechanism on the Pt nanoparticle surface, but rather lead to catalysts with enhanced specific activity compared to Pt/carbon systems. Different reasons for the enhancement in the specific activity are considered and discussed.
\end{abstract}

Keywords: Antimony-doped tin oxide $\cdot$ Catalysis $\cdot$ Cathode stability $\cdot$ Metal oxide $\cdot$ Support material

\section{Introduction}

Polymer electrolyte fuel cells (PEFCs) play a critical role towards the development of a sustainable hydrogen-basedeconomy.[1] Particularly for automotive applications, one of the main issues hindering PEFC widespread market penetration is related to the fast corrosion occurring at the cathode side during operation conditions. State-of-the-art PEFC cathodes are based on Pt nanoparticles supported on high surface area carbons. Under real operation conditions, the cathode of a PEFC can experience potentials as high as 1.5 $\mathrm{V}$ (RHE), which cause severe oxidation of the carbon support. [2] Carbon oxidation leads to severe corrosion of the carbon supporting structure with consequent detachment of Pt catalyst nanoparticles, and thus strong degradation of PEFC performance. ${ }^{[3]}$ Therefore, alternative support materials are needed to meet the durability requirements for practical applications. ${ }^{[1]}$ A promising approach is to replace carbon with conductive, high surface area metal

\footnotetext{
${ }^{\star}$ Correspondence: Dr. E. Fabbri

Electrochemistry Laboratory

Paul Scherrer Institut

OVGA/103A

$\mathrm{CH}-5232$ Villigen PSI

Tel.: +41563102795

E-Mail: emiliana.fabbri@psi.ch
}

oxides in their highest oxidation state. Indeed, besides being resistant to corrosion at high potentials, support materials for PEFCs must be also good electronic conductors, and low cost and high surface area materials. In the search for alternative Pt supports, several metal oxides have been investigated so far, such as $\mathrm{SnO}_{2}, \mathrm{TiO}_{2}$, $\mathrm{WO}_{3}$ etc. ${ }^{[4]}$ In the present work we selected $\mathrm{SnO}_{2}$-based supports because the Pourbaix diagram $^{[5]}$ and previous experimental studies ${ }^{[6]}$ have shown that $\mathrm{SnO}_{2}$ in its highest oxidation state is redox inactive in the potential range of interest and $\mathrm{pH}=1$. To develop a fundamental understanding of the $\mathrm{Pt} / \mathrm{SnO}_{2}$ system a multi-level approach has been adopted (Fig. 1). Model electrodes made of Pt nanoparticles deposited on

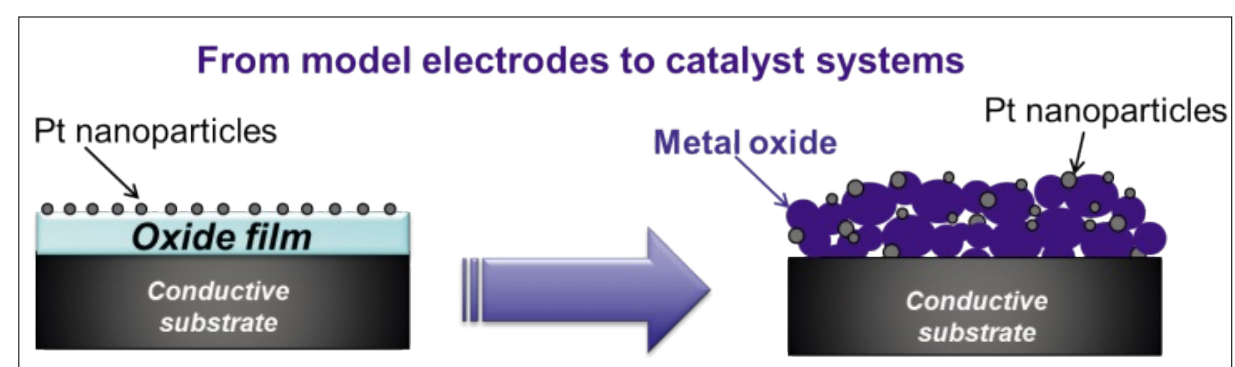

Fig. 1. Schematic representation of the main concept of the present work: A multi-level approach is adopted. Starting from the investigation of model electrodes based on $\mathrm{SnO}_{2}$ thin films supporting Pt nanoparticles towards the development of catalyst layers based on porous metal oxides supporting Pt nanoparticles.
$\mathrm{SnO}_{2}$ smooth, thin films have been firstly investigated. $\mathrm{SnO}_{2}$ films were produced by DC magnetron sputtering, controlling important physicochemical properties such as composition, microstructure and surface termination. ${ }^{[6]}$ Subsequently, porous catalyst layers have been developed by depositing Pt nanoparticles via a polyol synthesis method on porous $\mathrm{Sb}$-doped $\mathrm{SnO}_{2}$ supports. In fact $\mathrm{SnO}_{2}$, while being a perfect candidate material for model electrodes, exhibits poor electronic conductivity since it is a wide-band gap semiconductor with a band gap of $\sim 3.6 \mathrm{eV} .{ }^{[4 a]}$ Therefore, 5 at $\%$ $\mathrm{Sb}$-doped $\mathrm{SnO}_{2}\left(\mathrm{SbSnO}_{2}\right)$ supports have been synthesized by a modified sol-gel method to fulfil high surface area, high electrical conductivity, and corrosion sta- 
bility requirements. ${ }^{[7]}$ Fig. 1 summarizes the multi-level approach of the present work toward the development of durable catalysts.

\section{Experimental}

\section{Model Electrodes Preparation}

Tin oxide films were prepared by DC magnetron sputtering according to the procedure described in detail in ref. [6]. $\mathrm{Pt}$ with a loading of $2 \mu \mathrm{g} \mathrm{cm}^{-2}$ was deposited by DC magnetron sputtering on $\mathrm{SnO}_{2}$ supports from a metallic Pt target $(99.99 \%$ purity) using a discharge power of $50 \mathrm{~W}, 1 \mathrm{sec}$ deposition time, and $10 \mathrm{sccm}$ Ar flow. ${ }^{[6,8]}$

\section{Porous Oxide Support Synthesis}

$\mathrm{Sn}_{0.95} \mathrm{Sb}_{0.05} \mathrm{O}_{2} \quad\left(\mathrm{SbSnO}_{2}\right)$ powder has been synthesized by a modified sol-gel method. $\mathrm{SnCl}_{2}$ (Aldrich, 99.99\%) and $\mathrm{Sb}_{2} \mathrm{O}_{3}$ (Aldrich, 99.99\%) have been used as starting materials. Both $\mathrm{SnCl}_{2}$ and $\mathrm{Sb}_{2} \mathrm{O}_{3}$ were first dissolved in a $0.1 \mathrm{M} \mathrm{HNO}_{3}$ aqueous solution. After the two solutions were mixed, $\mathrm{NH}_{4} \mathrm{OH}$ solution (Aldrich) was used as a $\mathrm{pH}$ regulator $(\mathrm{pH} \sim 5)$. Chelation of the metal cations was then achieved by adding citric acid to the aqueous solution in a 2:1 ratio with respect to the total metal cations. Ethylene glycol was added in the last step to polymerize the organic precursor. Once the gel was obtained, it was washed and then dried at $150{ }^{\circ} \mathrm{C}$ overnight. The calcination process was carried out in $\mathrm{O}_{2}$ at $550{ }^{\circ} \mathrm{C}$ for $2 \mathrm{~h}$ with a heating/cooling rate of $5^{\circ} \mathrm{C} \mathrm{min}^{-1}$.

\section{Synthesis of Pt Nanoparticles Supported on $\mathrm{SbSnO}_{2}$}

Pt nanoparticles supported on $\mathrm{SbSnO}_{2}$ with $10 \mathrm{wt} \%$ calculated metal loading were prepared by a polyol method. ${ }^{[9]} 0.047 \mathrm{~g}$ of $\mathrm{H}_{2} \mathrm{PtCl}_{6} .6 \mathrm{H}_{2} \mathrm{O}$ (Alfa Aesar) was dissolved in $50 \mathrm{~mL}$ ethylene glycol in a three-necked flask. The $\mathrm{pH}$ of the solution was adjusted to 12 by the addition of $\mathrm{NaOH}$ under continuous vigorous stirring at room temperature. The reaction temperature was increased to $160{ }^{\circ} \mathrm{C}$ and refluxed for $2 \mathrm{~h}$. After cooling at room temperature, the $\mathrm{pH}$ was adjusted to 4 by $\mathrm{H}_{2} \mathrm{SO}_{4}$ (aq solution). Then, the calculated amount of oxide was added to this solution and maintained under stirring at room temperature for $4 \mathrm{~h}$. The final product was separated by filtration and washed several times with a mixture of water/ethanol $50 / 50 \%$ vol. and then dried in vacuum for $12 \mathrm{~h}$. For comparison, $\mathrm{Pt}$ nanoparticles were also deposited on commercial carbon Vulcan XC72 (BASF, specific surface area $250 \mathrm{~m}^{2} \mathrm{~g}^{-1}$ ) by the same polyol method. The carbon was used without any further treatment and the $\mathrm{Pt}$ content, measured by thermogravimetric analysis (TGA), was $18 \mathrm{wt} \%$.

\section{Physicochemical Characterization}

$\mathrm{SnSbO}_{2}, \mathrm{Pt} / \mathrm{SbSnO}_{2}$ and $\mathrm{Pt} /$ Vulcan were characterized by $\mathrm{X}$-ray diffraction (XRD, Bruker D8 system), BrunauerEmmett-Teller (BET) analysis, and transmission electron microscopy (TEM, FEI Morgagni 268, $120 \mathrm{kV}$, bright field acquisition).

\section{Electrode Preparation}

For the electrochemical characterization, $\mathrm{Pt} / \mathrm{SnSbO}_{2}$ and $\mathrm{Pt} / \mathrm{Vulcan}$ thin porous layers were prepared by drop-coating an electrode ink on glassy carbon disks using a modified thin-film RDE method.[10] The inks were prepared from a suspension made of $15 \mathrm{mg}$ of the catalytic powder, 20 $\mu \mathrm{l}$ of Nafion ${ }^{\circledR}$ solution (5\%wt in a wateraliphatic alcohol mixture, Sigma Aldrich), $4 \mathrm{ml}$ of isopropanol, and $1 \mathrm{ml}$ of water. The final loading was $\sim 28 \mu \mathrm{g}_{\mathrm{Pt}} \mathrm{cm}^{-2}$ both for $\mathrm{Pt} / \mathrm{SbSnO}_{2}$ and $\mathrm{Pt} /$ Vulcan catalysts. Preliminary tests have shown that a loading of $\sim 28 \mu \mathrm{g}_{\mathrm{P}_{\mathrm{t}}} \mathrm{cm}^{-2}$ allows full Pt utilization both for $\mathrm{Pt} / \mathrm{SbSnO}_{2}$ and $\mathrm{Pt} /$ Vulcan.

\section{Electrochemical Measurements}

The electrochemical measurements were performed in $0.1 \mathrm{M} \mathrm{HClO}_{4}$ using a saturated $\mathrm{Hg} / \mathrm{Hg}_{2} \mathrm{SO}_{4}$ reference electrode (ALS Co. Ltd, $0.719 \pm 1 \mathrm{~V} v s$. RHE) and a gold counter electrode, in a three electrode configuration. For the evaluation of the electrochemical active surface area (ECSA) of Pt nanoparticles, cyclic voltammetry (CV) measurements at $50 \mathrm{mV} \mathrm{s}^{-1}$ in $\mathrm{N}_{2}$-saturated $0.1 \mathrm{M} \mathrm{HClO}_{4}$ were performed. As described in ref. [11], for metal oxide supports $\mathrm{CV}$ measurements in $\mathrm{CO}$ saturated electrolyte at $50 \mathrm{mV} \mathrm{s}^{-1}$ with the electrode rotating at $1600 \mathrm{rpm}$ were also recorded for the correct evaluation of the ECSA. For sake of comparison, the same potential cycling in CO-saturated electrolyte was also performed for Pt/Vulcan catalysts. The oxygen reduction reaction (ORR) activity of the $\mathrm{Pt} / \mathrm{SnO}_{2}$ model electrodes and $\mathrm{Pt} / \mathrm{SnSbO}$ or $\mathrm{Pt} / \mathrm{Vulcan}$ catalysts was measured by the rotating disk electrode (RDE) technique in $\mathrm{O}_{2}$-saturated
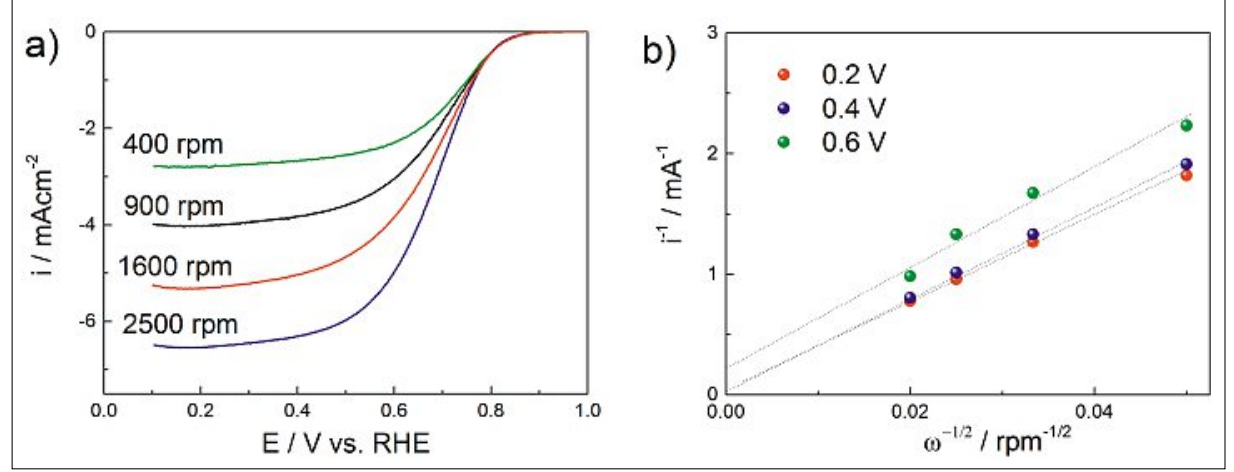

Fig. 2. a) ORR curves for $2 \mu \mathrm{g} \mathrm{cm}^{-2} \mathrm{Pt} / \mathrm{SnO}_{2}$ model electrode in $\mathrm{O}_{2}$-saturated $0.1 \mathrm{M} \mathrm{HClO}_{4}$ at different rotation speeds (cathodic direction of potential scan, $5 \mathrm{mV} \mathrm{s}^{-1}, \mathrm{RT}$ ); b) Koutecky-Levich plot relative to the ORR curves of $\mathrm{Pt} / \mathrm{SnO}_{2}$ model electrode.
$0.1 \mathrm{M} \mathrm{HClO}_{4}$ by cathodically scanning the disk electrode at different rotation speeds and scan rate of $5 \mathrm{mV} \mathrm{s}^{-1}$. The resulting disk polarization curves were corrected by the Ohmic drop in the electrolyte measured by electrochemical impedance spectroscopy.

\section{Results and Discussion}

\section{Model Electrodes}

Model electrodes were first investigated by developing $\mathrm{SnO}_{2}$ smooth thin films by DC magnetron sputtering; ${ }^{[6]}$ subsequently deposition of $\mathrm{Pt}$ nanoparticles of $2-3 \mathrm{~nm}$ in size $^{[6,12]}$ was also carried out by magnetron sputtering leading to an overall Pt loading of $2 \mu \mathrm{g} \mathrm{cm}^{-2}$. The electrochemical response of the model $\mathrm{Pt} / \mathrm{SnO}_{2}$ electrode towards the oxygen reduction reaction (ORR) was evaluated using the thin-film rotating disc electrode (RDE) technique. Fig. 2a shows a set of polarization curves in $\mathrm{O}_{2}$-saturated $0.1 \mathrm{M} \mathrm{HClO}_{4}$ at various rotation speeds (400-2500 rpm) and at a scan rate of $5 \mathrm{mV}$ $\mathrm{s}^{-1}$. The ORR of Pt on the $\mathrm{SnO}_{2}$ supports is under mixed kinetic-diffusion control in the potential range between 0.9 and $0.7 \mathrm{~V}$ (RHE), followed by a region where diffusion limiting currents (plateau between 0.6 and $0.2 \mathrm{~V}$ RHE) can be observed, comparable to those obtained for conventional $\mathrm{Pt} /$ carbon catalysts. $[12,13]$

Further insight into ORR kinetics can be obtained by evaluating the ORR polarization curves according to the KouteckyLevich analysis. The total measured current density (i) is given by the combination of the diffusion limited current density $\left(i_{D}\right)$ and the kinetic current density $\left(\mathrm{i}_{\mathrm{K}}\right)$, according to Eqn. (1):

$$
\begin{aligned}
& \frac{1}{\mathrm{i}}=\frac{1}{\mathrm{i}_{\mathrm{D}}}+\frac{1}{\mathrm{i}_{\mathrm{K}}}=\frac{1}{\mathrm{~B} \omega^{1 / 2}}+\frac{1}{\mathrm{i}_{\mathrm{K}}} \\
& \mathrm{B}=0.62 \cdot \mathrm{F} \cdot \mathrm{n} \cdot \mathrm{c}_{\mathrm{O}} \cdot \mathrm{D}_{\mathrm{O}}^{2 / 3} \cdot \mathrm{v}^{-1 / 6}
\end{aligned}
$$

where $\omega$ is the rotation rate, $F$ is the 
Faradaic constant, $\mathrm{n}$ the number of overall transferred electrons, $\mathrm{c}$ the oxygen solubility, $\mathrm{D}_{\mathrm{o}}$ the oxygen diffusion coefficient, and $v$ the kinematic viscosity of the electrolyte. The Koutecky-Levich plot depicted in Fig. $2 \mathrm{~b}$ for various potentials was derived from the RDE polarization curves in Fig. 2a. The linearity of the plots implies a first order dependence of ORR kinetics on $\mathrm{Pt} / \mathrm{SnO}_{2}$. The y-intercepts of Koutecky-Levich plots confirm the presence of kinetic limitations only above $0.6 \mathrm{~V}$ (RHE). From the slope of the dashed lines a B-factor of about $3.0 \times$ $10^{-2} \mathrm{~mA} \mathrm{rpm}^{-1}$ can be obtained $\left(\mathrm{D}_{\mathrm{O}}=1.93\right.$ $\times 10^{-5} \mathrm{~cm} \mathrm{~s}^{-1}, \mathrm{c}_{0}=1.26 \times 10^{-3} \mathrm{~mol} \mathrm{l}^{-1}, \mathrm{v}=$ $\left.1.009 \times 10^{-2} \mathrm{~cm} \mathrm{~s}^{-1}\right)^{[14]}$ indicating an almost 4-electron transfer process for the ORR.

\section{Porous Thin Film Electrodes}

After having established that $\mathrm{Pt}$ nanoparticles supported on $\mathrm{SnO}_{2}$ metal oxide thin film display a first order reaction and a 4-electron process for the ORR, porous catalyst layers were then developed using porous 5 at\% $\mathrm{Sb}$-doped $\mathrm{SnO}_{2}$ $\left(\mathrm{SbSnO}_{2}\right)$ powders produced by a modified sol-gel method. X-ray diffraction (XRD) analysis of as calcined $\mathrm{SbSnO}_{2}$ powder showed a single rutile phase (Fig. 3 ). The BET surface area of $\mathrm{SbSnO}_{2}$ support was $53 \pm 8 \mathrm{~m}^{2} \mathrm{~g}^{-1}$ and transmission electron microscopy (TEM) investigations revealed particle size in the range of 10 to $20 \mathrm{~nm}$ (Fig. 4a).

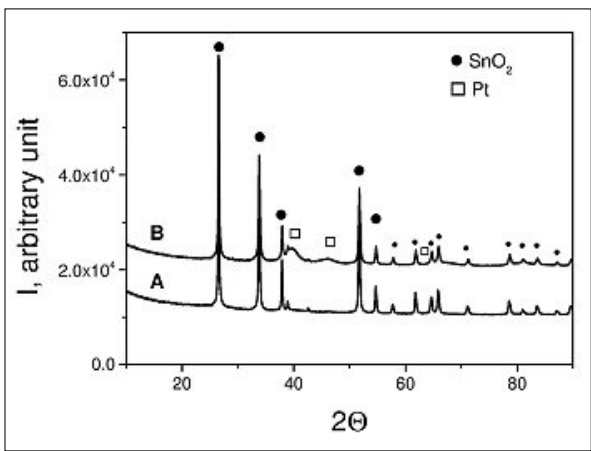

Fig. 3. XRD patterns of a) $\mathrm{SbSnO}_{2}$ powder after calcination and $b$ ) of synthesized Pt nanoparticles on $\mathrm{SbSnO}_{2}$.

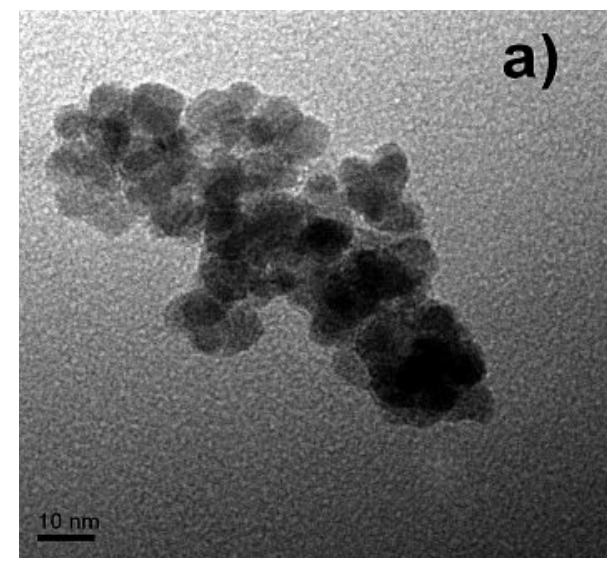

Pt nanoparticles were synthesized by means of a polyol method, and then supported on the $\mathrm{SbSnO}_{2}$ powder. The XRD pattern of $\mathrm{Pt}$ nanoparticles supported on $\mathrm{SbSnO}_{2}$ is also shown in Fig. 3; the $\mathrm{SbSnO}_{2}$ and $\mathrm{Pt}$ phases can be clearly identified. For comparison Pt nanoparticles were also synthesized by the same polyol method on commercial Vulcan XC72. The average Pt crystallite size, evaluated by applying the Scherrer equation, was $3.3 \mathrm{~nm}$ for $\mathrm{Pt} /$ $\mathrm{SbSnO}$ and $3.8 \mathrm{~nm}$ for $\mathrm{Pt} /$ Vulcan.

TEM analysis was also performed for the $\mathrm{Pt} / \mathrm{SbSnO}_{2}$ catalysts, but as shown in Fig. $4 \mathrm{~b}$ it is very difficult to distinguish the $\mathrm{Pt}$ and the $\mathrm{SbSnO}_{2}$ particles due to small size difference and low TEM contrast. Differently, TEM images of the Pt/Vulcan catalyst allow a clear identification of the synthesized Pt nanoparticles (Fig. 4c). For the latter samples, the average Pt particle size as revealed by TEM images is $\sim 3 \mathrm{~nm}$.

For the evaluation of the Pt active surface area normalized by the electrode geometric area (also known as roughness factor) the most used evaluation method consists of recording cyclic voltammograms in de-aerated electrolyte and then correcting the currents in the hydrogen underpotential deposition $\left(\mathrm{H}_{\text {upd }}\right)$ region by the capacitive currents from the double layer. However, this evaluation method cannot be applied to metal oxide supports as shown in ref. [11]. When metal oxide supports are used, recording a $\mathrm{CV}$ in $\mathrm{CO}$-saturated electrolyte is required since it represents the correct baseline for subtracting capacitive contributions from the $\mathrm{H}_{\text {upd }}$ signals. Therefore, for $\mathrm{Pt} / \mathrm{SbSnO}_{2}$ catalysts the $\mathrm{Pt}$ roughness factor has been calculated by subtracting the $\mathrm{CV}$ recorded in $\mathrm{CO}$-saturated electrolyte to the $\mathrm{CV}$ in $\mathrm{N}_{2}$-saturated electrolyte and then proceeding with the capacitive current correction. ${ }^{[11]}$ In contrast, for $\mathrm{Pt} /$ Vulcan catalysts the conventional double layer current subtraction to the $\mathrm{H}_{\text {upd }}$ signal has been used, even though potential cycling in CO-saturated electrolyte has also been performed for the sake of comparison. After having determined the charge

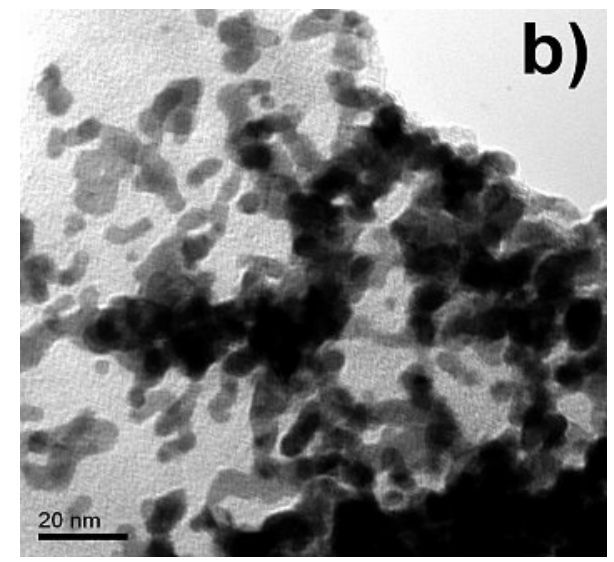

associated to the $\mathrm{H}_{\text {upd }}$, the Pt roughness factor was calculated assuming a hydrogen monolayer charge of $210 \mu \mathrm{C} \mathrm{cm}$. For the $\mathrm{Pt} / \mathrm{SbSnO}_{2}$ catalysts the roughness factor was determined to be $9.1 \pm 0.9 \mathrm{~cm}_{\mathrm{pt}}{ }^{2} / \mathrm{cm}^{2}$, while for the Pt/Vulcan a value of $20.6 \pm$ $0.5 \mathrm{~cm}_{\mathrm{Pt}}{ }^{2} / \mathrm{cm}^{2}$ was found.

As for the model electrodes, the ORR polarization curves of $\mathrm{Pt} / \mathrm{SbSnO}_{2}$ catalysts were recorded in $\mathrm{O}_{2}$-saturated $0.1 \mathrm{M}$ $\mathrm{HClO}_{4}$ at $5 \mathrm{mV} \mathrm{s}{ }^{-1}$ and at different rotation speeds (Fig. 5a). Also in case of 3D electrodes, the ORR curves resembled the typical mixed kinetic-diffusion control region followed by a plateau where diffusion limiting currents can be observed. The Koutecky-Levich analysis confirmed for the $\mathrm{Pt} / \mathrm{SbSnO}$ catalysts a first order reaction and a 4-electron process. The ORR curve at $1600 \mathrm{rpm}$ was correct by the mass transport limited current density $\left(i_{D}\right)$ according to Eqn (1), and the obtained kinetic current density normalized by the $\mathrm{Pt}$ roughness factor $\left(\mathrm{i}_{\mathrm{K} \text { spec }}\right)$ is shown in Fig. 5b. The specific activity, taken as the value of $\mathrm{i}_{\mathrm{K}, \mathrm{spec}}$ at $0.9 \mathrm{~V}$ (RHE) is $0.123 \pm$ $0.015 \mathrm{~mA} \mathrm{~cm}_{\mathrm{Pt}}^{-2}$ for $\mathrm{Pt} / \mathrm{SbSnO}_{2}$. The same kinetic current evaluation was also made for the Pt/Vulcan catalysts (Fig. 5b) and a specific activity value of $0.068 \pm 0.006$ $\mathrm{mA} \mathrm{cm}{ }_{\mathrm{Pt}}^{-2}$ was obtained in good agreement with literature data. ${ }^{[15]}$ The present results indicate that higher ORR specific activity (about a factor of 2) for Pt supported on $\mathrm{SbSnO}_{2}$ could be achieved compared to $\mathrm{Pt}$ supported on Vulcan.

Different reasons can account for the increased ORR specific activity of the $\mathrm{Pt} /$ $\mathrm{SbSnO}_{2}$ catalysts compared to that of $\mathrm{Pt} /$ Vulcan. It has been recently demonstrated that the Pt specific activity decreases moving from extended $\mathrm{Pt}$ surfaces/particle agglomerates to isolated nanoparticles, following an experimental master curve of specific activity vs. Pt electrochemical active surface area. ${ }^{[12]}$ Unfortunately it was not possible by TEM analysis to clearly identify the Pt nanoparticles supported on $\mathrm{SbSnO}_{2}$, making the direct comparison of the Pt nanoparticle distribution on the

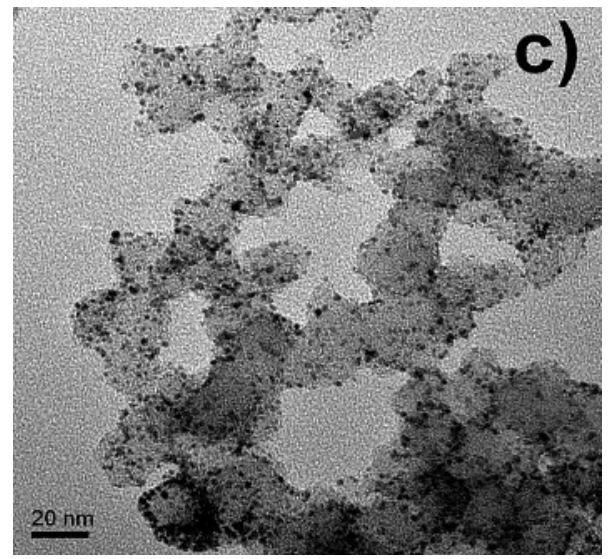

Fig. 4. TEM images of a) $\mathrm{SbSnO}_{2}$ powder; b) $\mathrm{Pt} / \mathrm{SbSnO}_{2}$ catalyst; c) $\mathrm{Pt} /$ Vulcan catalyst. 


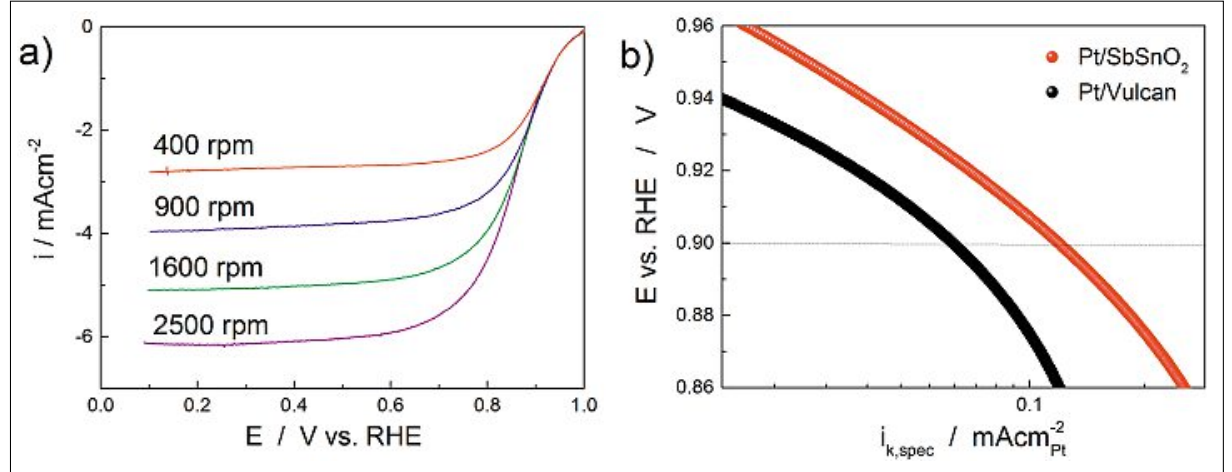

Fig. 5. a) ORR curves for $\mathrm{Pt} / \mathrm{SbSnO}_{2}$ catalysts in $\mathrm{O}_{2}$-saturated $0.1 \mathrm{M} \mathrm{HClO}_{4}$ at different rotation speeds (cathodic direction of potential scan, $5 \mathrm{mV} \mathrm{s}^{-1}$, RT); b) Mass-transport and ohmic drop correct ORR curves for $\mathrm{Pt} / \mathrm{SbSnO}_{2}$ and $\mathrm{Pt} /$ Vulcan catalysts measured at $1600 \mathrm{rpm}$ in $\mathrm{O}_{2}$-saturated $0.1 \mathrm{M} \mathrm{HClO}_{4}$ (cathodic direction of potential scan, $5 \mathrm{mVs}^{-1}, \mathrm{RT}$ ).

$\mathrm{SbSnO}_{2}$ and on the Vulcan support difficult. However, if a larger particle agglomeration takes place for the $\mathrm{Pt} / \mathrm{SbSnO}_{2}$ catalysts with respect to $\mathrm{Pt} / \mathrm{Vulcan}$ ones, the decrease in specific activity could be partially explained by a change in morphology. Besides the change in the Pt nanoparticle morphology, it cannot be excluded at present that for the $\mathrm{Pt} / \mathrm{SbSnO}_{2}$ catalysts a strong-metal-support-interaction (SMSI) takes place, modifying the Pt electronic structure and thus, in turn, its specific activity. The occurrence of a SMSI between $\mathrm{Pt}$ and $\mathrm{Sb}$-doped $\mathrm{SnO}_{2}{ }^{[16]}$ or between Pt and $\mathrm{TiO}_{2}$ and $\mathrm{WO}_{3}{ }^{[17]}$ has been recently reported. The observed superior specific activity of $\mathrm{Pt} / \mathrm{metal}$ oxide catalysts compared to $\mathrm{Pt} /$ carbon was correlated to a change in the $\mathrm{Pt}$ electronic structure, and particularly to a shift in the Pt4f peak in the XPS spectra. ${ }^{[16]}$ Further investigations are currently in progress in order to understand if a SMSI occurs also for the catalysts investigated in the present work and they will be published elsewhere.

\section{Conclusion}

A multi-level approach has been presented here with the aim of developing durable catalysts for application at the cathode side of PEFCs. Model electrodes made of $\mathrm{SnO}_{2}$ smooth thin films supporting $\mathrm{Pt}$ nanoparticles have been used to investigate the ORR mechanism and kinetics on Pt supported on $\mathrm{SnO}_{2}$ metal oxide. Subsequently, 3D catalysts were developed supporting Pt nanoparticles, synthesized by a modified polyol method, on a porous $5 \mathrm{at} \% \mathrm{Sb}-$ doped $\mathrm{SnO}_{2}$ structure $\left(\mathrm{SbSnO}_{2}\right)$. The $\mathrm{Pt} /$ $\mathrm{SbSnO}_{2}$ catalysts showed higher specific activity than Pt/Vulcan catalysts prepared using the same polyol method. Different reasons can account for the higher specific activity of $\mathrm{Pt}$ nanoparticles supported on $\mathrm{SbSnO}_{2}$ instead on high surface area carbon: i) different $\mathrm{Pt}$ nanoparticles morphology/distribution or ii) modification of the Pt electronic structure by the occurrence of a beneficial SMSI. Further investigations will elucidate which mechanism accounts for the enhanced $\mathrm{Pt} / \mathrm{SbSnO}_{2}$ activity.

\section{Acknowledgements}

This work was supported by CCEM Switzerland and Umicore AG \& Co KG within the project DuraCat. We gratefully thank Michael Horisberger for the sputtering of the Pt catalyst onto the $\mathrm{SbSnO}_{2}$ support.

Received: February 14, 2014

[1] A. Rabis, P. Rodriguez, T. J. Schmidt, ACS Catal. 2012, 2, 864.

[2] a) 'Polymer Electrolyte Fuel Cell Durability', Eds. F. N. Büchi, M. Inaba, T. J. Schmidt, Springer Science and Business Media LLC: New York, 2009, pp 199-221; b) C. A. Reiser, L. Bregoli, T. W. Patterson, J. S. Yi, J. D. L. Yang, M. L. Perry, T. D. Jarvi, Electrochem. Solid State Lett. 2005, 8, A273.

[3] H. Schulenburg, B. Schwanitz, N. Linse, G. G. Scherer, A. Wokaun, J. Krbanjevic, R. Grothausmann, I. Manke, J. Phys. Chem. C 2011, 115, 14236.

[4] a) E. Antolini, E. R. Gonzalez, Solid State Ionics 2009, 180, 746; b) Y. Y. Shao, J. Liu, Y. Wang, Y. H. Lin, J. Mater. Chem. 2009, 19, 46; c) S. Sharma, B. G. Pollet, J. Power Sources 2012, 208, 96.

[5] M. Pourbaix, 'Atlas of Electrochemical Equilibria', Cebelcor, 1974.

[6] A. Rabis, D. Kramer, E. Fabbri, M. Worsdale, R. Kötz, T. J. Schmidt, J. Phys. Chem. C 2014, submitted.

[7] E. Fabbri, A. Rabis, R. Kötz, T. J. Schmidt, PhysChemChemPhys 2014, doi: 10.1039/ C4CP00238E.

[8] A. Rabis, E. Fabbri, A. Foelske, M. Horisberger, R. Kötz, T. J. Schmidt, ECS Trans. 2013, 50, 9.

[9] a) F. Fievet, J. P. Lagier, B. Blin, B. Beaudoin, M. Figlarz, Solid State Ionics 1989, 32, 198; b) C. Grolleau, C. Coutanceau, F. Pierre, J. M. Leger, J. Power Sources 2010, 195, 1569.

[10] T. J. Schmidt, H. A. Gasteiger, G. D. Stab, P. M. Urban, D. M. Kolb, R. J. Behm, J. Electrochem. Soc. 1998, 145, 2354.

[11] T. Binninger, E. Fabbri, R. Kötz, T. J. Schmidt, J. Electrochem. Soc. 2014, 161, H121.

[12] E. Fabbri, S. Taylor, A. Rabis, P. Levecque, O. Conrad, R. Kötz, T. J. Schmidt, ChemCatChem 2014, DOI: $10.1002 /$ cctc. 201300987.

[13] a) K. J. J. Mayrhofer, B. B. Blizanac, M. Arenz, V. R. Stamenkovic, P. N. Ross, N. M. Markovic, J. Phys. Chem. B 2005, 109, 14433; b) V. Stamenkovic, T. J. Schmidt, P. N. Ross, N. M. Markovic, J. Phys. Chem. B 2002, 106, 11970.

[14] B. Schwanitz, A. Rabis, M. Horisberger, G. G. Scherer, T. J. Schmidt, Chimia 2012, 66, 110.

[15] U. A. Paulus, T. J. Schmidt, H. A. Gasteiger, R. J. Behm, J. Electroanal. Chem. 2001, 495, 134.

[16] M. Yin, J. Y. Xu, Q. F. Li, J. O. Jensen, Y. J. Huang, L. N. Cleemann, N. J. Bjerrum, W. Xing, Appl. Catal. B 2014, 144, 112.

[17] A. Lewera, L. Timperman, A. Roguska, N. Alonso-Vante, J. Phys. Chem. C 2011, 115, 20153. 